\title{
Evaluation of 18 to 45 Years Old Women's Mental Health and Social Effective Factors (Case Study: Women Living in Gerash)
}

\author{
Mahboubeh Mehrabi \\ Department of Social Science, Payame Noor University, \\ P.O. Box 19395-3697, Tehran, Iran \\ jame_mehrabi@yahoo.com \\ Zhila Abbasi \\ MA of Sociology from Azad University of Dehaghan, Dehaghan, Iran \\ abbasi_zh@yahoo.com \\ Vahid Haghgoo \\ MS of Information Technology Engineering \\ From Shiraz University, Shiraz, Iran \\ (haghgoo.vahid@gmail.com
}

Doi:10.5901/mjss.2014.v5n4p557

\begin{abstract}
Nowadays the life is constantly changing and human being more than any other living organism, is subject to change. Human being as a social organism recognizes the importance and value of these issues. Sometimes these problems cause disorders in human life and distort mental health. This study aimed to investigate mental health of Gerash's women and social factors that affect it by navigational method and by using questionnaires and interviews were conducted among 250 individuals. Finally, the obtained data were analyzed by using SPSS statistical software. According to the results of the variables of families interfering in matrimony life, participation in decision-making at home, housework sharing and number of children have a significant relation with mental health of women.
\end{abstract}

Keywords: mental health, interfering in family life and participation of women in decision-making at home.

\section{Introduction}

Mental health is a concept that indicates how we think, feel and performance in dealing with the life situations and it depends on our understanding of ourselves and our lives. Also, depending on the range of mental health, our performance in stress management, communication with others, evaluations and choices are different. In fact, mental health is more than the absence of mental illness. What is certain is that mental health is very important like physical health. Generally, people who have mental health, have a positive attitude towards life. They are prepared to deal with the problems of life. They have good feeling about themselves and others. They are responsible at work and their relationships. Because if we have mental health, we will expect the best things in life and we are ready to deal with any incident. We can achieve balanced and joyful spirit better by learning characteristics of mental health. Women as fundamental members of society have an important role in determining directions, motivations, upheavals and formation of their character. Today's children that are taking tomorrow's social roles are growing in provided training areas by women and are learning and choosing their social and individual roles. Formation of these roles has a close relationship with roles of mother, wife and woman's education. All research and psychological studies have confirmed this fact that the mental health of children, is depending on their mother's mental health. Even the behavior, attitude and mental situation of woman can highly determine the mental and behavioral situation of wife and her environment - Akuchekian, Shahla (1997).

How is mental health of women in Gerash influenced by some social factors? Factors such as housework sharing, participation in decision-making at home, interfering of families in the matrimony life and number of their children . This study was performed in order to answer above questions and queries. 


\section{Statement of the Problem}

The World Health Organization (WHO) defined health as a set of welfare and complete physical, mental and social comfort, which none of them is superior to another Soltanian, Alireza. Fatima Bahraini, Soudabeh Namazi, Mohammad Amiri, Hossein Ghaedi, Gholamreza Kohan (2004). Mental health is considered as one of the health dimensions. Several definitions have been proposed for mental health until now, that have emphasized on the importance of personal integrity. Some ones consider the mental health as a balance between members and environment to achieve prosperity. Some others explain mental health as a psychological maturity condition, that is, maximum effectiveness, and satisfaction from the interaction of individual and social that is including, feelings, and positive feedbacks of own and others. Throughout history, humanity has undergone changes in lifestyle, social and economic issues. Trying to industrialization and urbanization and mechanization and adapting to modern lifestyles, had a reverse effect on mental health. Progress, dynamism and promotion of any population are not in something except the healthy elements of the society, members that have not only a suitable physical condition but also have a moderate, and good mental stat. undoubtedly, the main result of symmetry of physical and mental health, is a successful community with a bright future. Sometimes social problems have disrupted a man's life and endanger the mental health. As human for releasing from the problems goes far from society, introspect and then subsequent problems such as depression, anxiety, poor social functionality, and even physical complaints appear for human. Found that both depression and anxiety disorders are common among the general public to complain. According to WHO, 52 million people in all over the world at the different ages suffer from severe mental illness and 250 million of people have mild mental illnesses, in Iran, these statistics is not lower than other countries Soltanian, Alireza. Fatima Bahraini, Soudabeh Namazi, Mohammad Amiri, Hossein Ghaedi, Gholamreza Kohan (2004). In the national study of health and disease in Iran by using a 28GHQ questionnaire, disorders in people over 15 years was reported $21 \%$ Hosseini S H, Mousavi M H. (2007).

The highest prevalence of disorders was in Chahar Mahal and Bakhtiari (1/39\%), respectively Noorbala A A. Kazem, M. (1999). According to studies conducted in Europe and the United States has been estimated that between 9 to 26 percent of women and 5 to 12 percent of men in their lifetime, had experienced a major type of depression. Thus, women are two times more than men suffer from depression and this ratio has been reported in clinical populations to Robinson KL, McBeth J, Macfarlane GJ.(2004), Black,C,V,R,\&Clar,A.W.(1987). Half of the population of every society usually is women; therefore, considering their mental health has critical impact on whole the society. Mental health is required to maintain social, occupational and educational and family functionality of population Bahrainian S A, Nour Ali A. (2004). Knowing the current status of people's mental health who are planning for the future of the community, will help to get reasonable successes. The main problem is preventing things that cause interruptions in mental health of people and therefore may have negative consequences. This study aimed to assess the mental health status of women living in Gerash and social factors that are effective (the housework sharing, women's participation in decision-making at home, others interfering in matrimony life and number of children).

\section{Hypotheses of Study}

- Hypothesis 1 - There is a relationship between the housework sharing and mental health of women.

- Hypothesis 2 - There is a relationship between the rate of female participation in decision-making in home and mental health.

- Hypothesis 3 - There is a relationship between respondent's families interfering in matrimony life and psychological health.

- Hypothesis 4 - There is a relationship between respondent's number of children and her mental health.

\section{Defining Variables}

Housework sharing: the research mentioned housework sharing such as cleaning, washing dishes, cooking, etc. between men and women and children.

Participation in decision making: in this study with those items in the "freedom of the individual" "the role of women in decision-making" and "having open relations with spouse" is measured as a part of the significance limit of this variable.

Families' interfering in matrimony life of couples: the purpose of family is interfering of men or woman family in matrimony life of couples. 
Number of children: children's number of a woman that was born.

Mental Health: World Health Organization: "mental health is the ability to communicate harmonious with others, and modification of personal and social environments and to resolve conflicts and personal desires in a logical, fair and reasonable way" Milanifar, Behrouz. (1991).

In this study, we have used 10 dimensions of somatization, mental and practical obsessive, interpersonal sensitivity, depression, anxiety, hostility and anxiety in fear mood, paranoid, psychosis and general inquiries. These indicators were included in the standard measurement of mental health questionnaire SCL90-R.

\section{The Theoretical Study}

\subsection{Background of Research}

KHaghani-Fard (1390) conducted a study entitled in "The Role of Violence against Women, gender socialization and social capital in predicting mental health of women in Tehran. The present study investigated the role of violence against women, gender socialization and social capital in predicting mental health by involving 376 of women living in Tehran. The study was descriptive - correlational. Results showed that women have greater access to social and family capitals have better mental health. How much the following patterns of gender socialization and violence against women is less, women have better mental health. Multiple regression analysis showed that socialization, supports and social capitals have a decisive contribution in predicting level of the mental health of women Khaghanifard, Mitra (2011).

Sepehrmanesh (1387) did a research entitled in "Mental health and associated factors among women living in Kashan city". Present study was done in a descriptive - analytic study on 400 young women from 20 to 40 years old. The results indicate that 40 percent of women in Kashan are suspected of mental health disorders. These women had higher average in two subscales of anxiety and physical symptoms. Mental health of women was significantly associated with age, number of children, education and the economic situation Sepehrmanesh , Zahra. (2009).

Mosallanejad et.al (1386) did a research on "mental health of women during pregnancy and psychological related factors with it in Jahrom city". This study was done among 214 pregnant women attending gynecology clinics in Jahrom city, with descriptive - sectional method by scl90 test with 90 questions. Results showed that the averages obtained from psychological disorders, the highest average was related to depression and the lowest average was related to psychotic and $43 \%$ of the total was suspicious for mental disorders. Results showed significant relationships between demographic variables and mental health Lily Mossalanejad, Amir Kheshti, Ehsan Gholami (2007).

Soltanian et al (1383) did a research entitled in" the mental health of high school students in Bushehr its influencing factors at 1382-83 academic year". Factors such as parents' education, exercising, visiting relatives, behavior of parents at home, and the management of parents at home, respect to others and respect to rights of others at home have a significant relationship with mental health of students Soltanian, Alireza. Fatima Bahraini, Soudabeh Namazi, Mohammad Amiri, Hossein Ghaedi, Gholamreza Kohan (2004).

Asgharipour did a research with topic of "mental health of first grade male and female students of high school in Mashhad and effects of adaptive consults provided by school counselors on their mental health". The results showed that, at all levels, abnormal levels in girls are more than boys. Also adaptive consults had not any significant role on reducing mental health disorder's level of students Asgharipoor, Hamid and Negar Asgharipoor and Manoochehr Fazlikhany (2004).

Janani did a study entitled in "The Relationship of family's functionality and general health of the children". Analysis of the data showed that generally family's functionality and general health of the students have a meaningful relationship. Between assertiveness and self- expression and public health of students, a significant positive relationship was observed. The results obtained in the theoretical and investigative aspects of the research show that interactions within families are related with the health rate of their children Janani, Katayun. (2001).

Zareei (1380) did a research entitled in "compression of mental health of women in monogamy family and women in multi-gamy family, in Ahwaz city". For assessing the mental health of these two families SCL25 questionnaire of mental health was used Najarian, Bahman and Davoodi, Iran (2001), which is built based on the SCL90-R Mental Health Scale. Stress of being wife of a man with some wives, disturbs mental balance of these families' women and make them prone to mental illness. Turmoil of breaks in natural form of family will result in anti-compromising opinion and reduction in life satisfaction of women, anger, lack of behavior control and etc. Zarei, Eqbal (1994). 


\subsection{Theoretical framework of research}

Holistic view of psychological health is considered in mental, social and physical aspects. Psychological health is a definition that psychologists and sociologists that are presented about the efficacy and suitable psychological functionality. Aristotle in Ethics book, says that every person is that much healthy that could develop own human interactions. Because human has the highest performance of intelligence so the best life is intellectual life and mental health means a kind of life that logic governs it.

\subsubsection{Freud's view (1856)}

According to Freud, specific characteristic is required for psychological health and the first characteristic is selfawareness. It means that whatever in unconscious causes a problem must be conscious. Self-consciousness is a key element of psychological health. The ultimate measure of mental health in Freud's view is unawareness about interests and general enthusiasm. In Freud's view conventional man is one who passed stages of psychosexual development successfully. And did not stay at any stage more that its limit. However in Freud's view few man is considered normal, and every individual is one way eccentric Khodarahimi, S. (1994).

\subsubsection{Adler's psychological, social and biological theory (1870)}

In Adler 's view mental health means having clear goals in life, having a solid and firm philosophy for living , optimal and sustainable family and social relationships, being beneficial for fellowmen, Courage, bravery and determination, being able to control emotions, having a perfection goal and self- realization , accepting mistakes and strive to fix mistakes as possible Khodarahimi, S. (1994).

\subsubsection{Ericsson's theory (1963)}

As Freud that gives a big importance to unconscious, in his theories Ericsson believes in "I". Mental health is defined and described in connection with "I". In general, Ericsson believes that there are certain characteristic in psychologically healthy person that makes him/her different from person who has not this element. Ericsson thinks these traits become meaningful in society and based on this individuals who live in society, whereas they have mental health if they be free from conflicts, have a clear ability and talent, be skilled in own job, have infinite Initiative, get feedback from every moment of his career and have clear moral and understandable theory about the process of life Khodarahimi, S. (1995).

\subsubsection{Theory of Kurt Lewin (1890)}

Kurt Lewin's is known for field theory among psychologists. Lewin comments in relation to mental health, the health and psychological perfection cause segregation and more differentiation between person and psychological environment and make firm boundaries of psychological system. So in Lewin's point of view psychologicaly healthy person is one who can distinguish between himself/herself and his/her psychological condition Khodarahimi, S. (1995).

\subsubsection{Theory of Carl Rogers (1902)}

According to Rogers, how much the mental health is more will feel and experience more freedom and choice. In point of view of Rogers healthy human is an unlimited creature in thought and action Khodarahimi, S. (1995).

One of the basic and complex concepts of human's world is concept of health. World Health Organization defines health as "state of complete physical, psychological and social well-being, and not only the absence of disease or disability" Babapoor, Khairuddin, Jalil, (2003). In general, the definition of health appeared from models that are part of the beliefs of scientists. Accordingly, three important models have always been considered in defining health:

Medical model: This model mainly focuses on explaining biological and physiological of health.

Environmental model: This model has emerged of the new analysis of ecosystem and environmental threats for human health. In this model, health is presented on base of individual adaptation to the environment on the changing time.

Holistic model: This model defines health in terms of the whole person and aspects of biological, physiological, 
psychological, emotional, social, spiritual and environmental of person and focuses on optimal health, disease prevention and positive mental and emotional moods Babapoor, Khairuddin, Jalil, (2003). This model holds that: health is not static but also it is a dynamic process that reflects all the decisions and daily activities of living Adlyn et al (1999).

\section{Research Framework}

This survey was done by measurement assessing the mental health of women, SCL 90 - R standard questionnaire, was used. The information of this questionnaire was collected by face to face interview with respondents. Studied location is Gerash City that is located on the south of Fars state. Sample was 250 women living in Gerash, which are chosen randomly.Results are processed by using SPSS software and are analyzed by statistical techniques.

\section{Validity and Reliability of Assessment Tools}

In this study for validity facial validity and for assessing reliability retest and internal consistency were used. As can be seen in Table-1, the results of Cronbach's alpha suggest that the value coefficients for the different spectra are acceptable.

Table 1: Results of reliability test for a questionnaire spectrums

\begin{tabular}{|l|c|c|}
\hline \multicolumn{1}{|c|}{ Spectra } & Number of speech & Cronbach's Alpha Coefficient \\
\hline Respondent's participation in decision making at home & 7 & 0.76 \\
\hline Mental health & 90 & 0.98 \\
\hline Sharing of housework & 8 & 0.75 \\
\hline
\end{tabular}

\section{Data Analysis}

\subsection{Descriptive Statistics}

Table 2: shows the age distribution of respondents. As you are observing more than 70 percent of respondents are in range of 20-34 years old that most of them are 20-24 years old. The average age of women is 28 years, minimum is 17 and maximum is 46 years.

Table 2: Frequency distribution and frequency percentage of respondents' age

\begin{tabular}{|c|c|c|}
\hline Age group & Frequency & Frequency Percentage \\
\hline $15-19$ & 16 & 6.8 \\
\hline $20-24$ & 71 & 29.9 \\
\hline $25-29$ & 63 & 26.6 \\
\hline $30-34$ & 38 & 16.1 \\
\hline $35-39$ & 29 & 12.2 \\
\hline+40 & 18 & 7.6 \\
\hline
\end{tabular}

Table 3: It shows women's education. As you can see, more than seventy percent of respondents have high or middle school diploma. Average of women's education is 11 years, minimum is 3 and maximum is 19 years.

Table 3: Frequency distribution and frequency percentage of respondents ' education

\begin{tabular}{|c|c|c|}
\hline Education & Frequency & Frequency percentage \\
\hline Elementary & 19 & 8 \\
\hline Middle school & 66 & 27.8 \\
\hline High school & 114 & 48.2 \\
\hline University & 27 & 11.3 \\
\hline
\end{tabular}

Table 4: It shows the number of children. As you can see, almost sixty percent of respondents have one or two children. 
It is noteworthy, that seventy percent of respondents are 20 to 34 years old, so these figures are not unexpected. Average number of children is 2 , the minimum is 0 and maximum is 7 children.

Table 4: Frequency distribution and frequency percentage of respondents' children

\begin{tabular}{|c|c|c|}
\hline Number of children & Frequency & Frequency percentage \\
\hline 0 & 39 & 16.5 \\
\hline $1-2$ & 138 & 58.2 \\
\hline $3-4$ & 33 & 14 \\
\hline $5-6$ & 10 & 4.2 \\
\hline+7 & 1 & 0.4 \\
\hline
\end{tabular}

\subsection{Inference Statistics}

Theory 1: It seems that there is a relationship between the ten dimensions of women's mental health and housework sharing.

Table 5: It shows the relationship between their mental health and housework sharing. As you can see, these two variables' relationship of 10 dimensions of mental health is significant. According to the results the size variable of the housework sharing is not significant in hostility, somatization, anxiety in fear mood, interpersonal sensitivity, anxiety, paranoia and psychosis and general inquiries. But in other two dimensions shows in mental and practical obsessive: 3.13 and depression: 1.15 percent of correlation. R2 assigning coefficient in the above order indicates that 8.1 and 3.2 percent of the variation in the dependent variable by the independent variables of housework sharing is explainable. Standardized assigning coefficient shows, 4.1 and 9.1 of the variation in the dependent variable of the mental health by the independent variables of housework sharing is explainable in statistical universe. Beta shows that relationship between mental health variable and housework sharing is an inverse relation. This means that if housework sharing rate is high so the absence of mental health is low. In other words, how much housework sharing is greater, mental health is more. The B's value indicates, for each unit increment in the independent variable how much value is increasing or decreasing in the dependent variable. Therefore, by considering value of $\mathrm{F}$ and $\mathrm{T}$ and meaningfully level this theory is accepted in the two dimension.

Table 5: Evaluation of Relationship between housework sharing and ten dimensions of mental health

\begin{tabular}{|l|c|c|c|c|c|c|c|c|c|}
\hline Mental health dimensions & $\mathrm{R}$ & $\mathrm{R} 2$ & $\mathrm{R} 2 . \mathrm{Ad}$ & Standard error & $\mathrm{B}$ coefficient & Beta & Value of T & Value of F & Significance level \\
\hline hostility & 0.108 & 0.012 & 0.007 & 0.6813 & -0.013 & -0.108 & -1.666 & 0.7762 & 0.097 \\
\hline somatization & 0.031 & 0.001 & -0.003 & 0.7217 & -0.004 & -0.031 & -0.47 & 0.221 & 0.639 \\
\hline mental and practical obsessive & 0.133 & 0.018 & 0.014 & 0.7109 & -0.017 & -0.133 & -2.059 & 4.239 & 0.041 \\
\hline interpersonal sensitivity & 0.082 & 0.007 & 0.002 & 0.6924 & -0.01 & -0.082 & -1.258 & 1.584 & 0.209 \\
\hline depression & 0.151 & 0.023 & 0.019 & 0.7251 & -0.02 & -0.151 & -2.335 & 5.453 & 0.02 \\
\hline anxiety & 0.05 & 0.003 & -0.002 & 0.7891 & -0.007 & -0.05 & -0.769 & 0.591 & 0.443 \\
\hline anxiety in fear mood & 0.033 & 0.001 & -0.003 & 0.6809 & -0.004 & -0.033 & -0.503 & 0.253 & 0.615 \\
\hline paranoia & 0.046 & 0.002 & -0.002 & 0.7551 & -0.007 & -0.756 & 0.572 & 0.45 & 0.512 \\
\hline psychosis & 0.03 & 0.001 & -0.003 & 0.6429 & -0.004 & -0.03 & -0.466 & 0.217 & 0.641 \\
\hline General inquiries & 0.061 & 0.004 & -0.001 & 0.7775 & -0.009 & -0.061 & 0.934 & 0.872 & 0.351 \\
\hline
\end{tabular}

Theory 2: It seems that there is a relation between the women participation in home decisions and mental health.

Table 6: It shows the relationship between the women's participation in decision-making at home and their mental health. As you can see, the relationship of this variable with 10 dimensions of mental health is significant. According to the results varied women's involvement in decision-making at home shows in hostility and somatization dimensions: 17.6 , mental and practical obsessive and anxiety in fear mood dimensions: 17 , interpersonal sensitivity : 26.6, Depression : 22.1 , anxiety : 17.1 paranoid: 14.2 and psychosis : 14.9 percent of correlation with mental health . Coefficient of R2 indicates 3.1, 3.1, 2.9, 7.1, 9.9, 9.4, 2.2, 2, 2.2, 1.2 percent of changes in the dependent variable on the participation of women could be explained by the independent variables in above order. Standardized coefficient shows , $7.7,2.2,2.5$, $6.7,5.5,2.4,2.5,1.6,1.8,0.8$ of changes in the mental health depended variable by the independent variable of participation of women in the statistical universe could be explained. Beta shows that relationship between mental health 
and participation is an inverse relation. This means how much participation of women in decision making is greater, lack of mental health is lower. In other words, how much the participation is greater, the psychological health is greater. The $B$ indicates, for each unit increment in the independent variable how much dependent variable is increasing or decreasing. Therefore, by considering $\mathrm{F}$ and $\mathrm{T}$ values and significance level this theory is accepted.

Table 6: Evaluation of Relationship between the women's involvement in decision-making at home and the ten dimensions of mental health

\begin{tabular}{|l|c|c|c|c|c|c|c|c|c|}
\hline \multicolumn{1}{|c|}{ Mental health dimensions } & $\mathrm{R}$ & $\mathrm{R} 2$ & R2.Ad & Standard error & B coefficient & Beta & Value of T & Value of F & Significance level \\
\hline hostility & 0.176 & 0.031 & 0.027 & 0.6747 & -0.03 & -0.176 & -2.738 & 0.499 & 0.007 \\
\hline Somatization & 0.176 & 0.031 & 0.027 & 0.7108 & -0.032 & -0.176 & -2.741 & 7.514 & 0.007 \\
\hline mental and practical obsessive & 0.17 & 0.029 & 0.025 & 0.7069 & -0.031 & -0.17 & -4.238 & 6.991 & 0.009 \\
\hline interpersonal sensitivity & 0.266 & 0.071 & 0.067 & 0.6696 & -0.046 & -0.266 & -3.474 & 17.961 & 0.000 \\
\hline depression & 0.221 & 0.049 & 0.045 & 0.7154 & -0.041 & -0.221 & -2.658 & 12.072 & 0.001 \\
\hline anxiety & 0.171 & 0.029 & 0.025 & 0.7784 & -0.034 & -0.171 & -2.64 & 0.591 & 0.008 \\
\hline anxiety in fear mood & 0.17 & 0.029 & 0.025 & 0.6714 & -0.029 & -0.17 & -0.503 & 7.067 & 0.009 \\
\hline paranoia & 0.142 & 0.02 & 0.016 & 0.7483 & -0.027 & -0.142 & 2.205 & 6.97 & 0.028 \\
\hline psychosis & 0.149 & 0.022 & 0.018 & 0.6359 & -0.024 & -0.149 & -2.311 & 4.86 & 0.022 \\
\hline General inquiries & 0.109 & 0.012 & 0.008 & 0.7744 & -0.021 & -0.109 & -1.673 & 5.343 & 0.096 \\
\hline
\end{tabular}

Theory 3: It seems that there is a relationship between interfering of the family in personal life of respondent and her mental health.Table 7: It shows Relationship between the families interfering in the personal lives of women with mental health. To investigate this relationship because this variable is at the nominal level has two -story, we used independent T-test. As we see in the table, this variable in interpersonal sensitivity, hostility, mental and practical obsessive, depression, anxiety, and anxiety in fear mood, paranoid ideation, and psychosis dimensions is significant and a significant difference is mentioned in averages. According to the $\mathrm{T}$ and their significance level, $\mathrm{H} 1$ in these dimensions is accepted based on relationship between mental health of women and families interfering in the personal lives of women. In other words, theory (3) about above dimensions is acceptable. According to these tables, women that families' interfering in their personal lives is lower have a better mental health than others.

Table 7: Evaluation of relationship between the degree of family interfering and ten dimensions of mental health

\begin{tabular}{|c|c|c|c|c|c|c|c|}
\hline Mental health dimensions & $\begin{array}{c}\text { Family } \\
\text { interfering }\end{array}$ & Frequency & Average & $\begin{array}{l}\text { Standard } \\
\text { deviation }\end{array}$ & $\begin{array}{c}\text { Standard's error of } \\
\text { average }\end{array}$ & $\begin{array}{c}\text { Value of } \\
\mathrm{T}\end{array}$ & $\begin{array}{c}\text { Significance } \\
\text { level }\end{array}$ \\
\hline \multirow[t]{2}{*}{ hostility } & Yes & 48 & 1.20139 & 0.734942 & 0.106080 & \multirow{2}{*}{2.01} & \multirow{2}{*}{0.049} \\
\hline & No & 189 & 0.96774 & 0.660675 & 0.048443 & & \\
\hline \multirow{2}{*}{ somatization } & Yes & 48 & 1.5573 & 0.67856 & 0.09794 & \multirow{2}{*}{1.894} & \multirow{2}{*}{0.062} \\
\hline & No & 189 & 1.3468 & 0.71663 & 0.05255 & & \\
\hline \multirow{2}{*}{$\begin{array}{l}\text { mental and practical } \\
\text { obsessive }\end{array}$} & \multirow{2}{*}{ Yes } & 48 & 1.55 & 0.71340 & 0.10297 & \multirow[b]{2}{*}{1.467} & \multirow[b]{2}{*}{0.147} \\
\hline & & 189 & 1.3806 & 0.71081 & 0.05212 & & \\
\hline \multirow[b]{2}{*}{ interpersonal sensitivity } & \multirow{2}{*}{ Yes } & 48 & 1.5995 & 0.69775 & 0.10071 & \multirow{2}{*}{2.899} & \multirow{2}{*}{0.005} \\
\hline & & 189 & 1.2748 & 0.66938 & 0.04908 & & \\
\hline \multirow{2}{*}{ depression } & Yes & 48 & 1.5929 & 0.77995 & 0.11258 & \multirow{2}{*}{2.362} & \multirow{2}{*}{0.021} \\
\hline & No & 189 & 1.3002 & 0.70633 & 0.05179 & & \\
\hline \multirow{2}{*}{ anxiety } & Yes & 48 & 1.5229 & 0.79258 & 0.1440 & \multirow{2}{*}{2.468} & \multirow{2}{*}{0.016} \\
\hline & No & 189 & 1.2086 & 0.76387 & 0.05601 & & \\
\hline \multirow{2}{*}{ anxiety in fear mood } & Yes & 48 & 1.0179 & 0.65606 & 0.09469 & \multirow{2}{*}{2.04} & \multirow{2}{*}{0.045} \\
\hline & No & 189 & 0.7995 & 0.68025 & 0.04988 & & \\
\hline \multirow{2}{*}{ paranoia } & Yes & 48 & 1.9722 & 0.69729 & 0.10064 & \multirow{2}{*}{4.897} & \multirow{2}{*}{0.000} \\
\hline & No & 189 & 1.4149 & 0.72498 & 0.05316 & & \\
\hline \multirow{2}{*}{ psychosis } & Yes & 48 & 1.15 & 0.72258 & 0.10430 & \multirow{2}{*}{2.822} & \multirow{2}{*}{0.006} \\
\hline & No & 189 & 0.8312 & 0.59247 & 0.04344 & & \\
\hline \multirow{2}{*}{ General inquiries } & Yes & 48 & 1.6905 & 0.70992 & 0.10247 & \multirow{2}{*}{1.268} & \multirow{2}{*}{0.209} \\
\hline & No & 189 & 1.5415 & 0.78519 & 0.05757 & & \\
\hline
\end{tabular}


Theory 4: It seems that there is a relationship between the number of respondent's children and her mental health.

Table 8: It shows the relationship between numbers of respondent's children and their mental health. As you can see, the relationship of this variable with 10 dimension of mental health is significant. According to the results children's number of respondents in dimensions of hostility: 13.5 , somatization : 12.72 , mental and practical obsessive: 19.2 , anxiety in fear mood : 20.9 , interpersonal sensitivity : 27.6, depression : 22.7 , anxiety : 21.1 paranoid :26.3 and psychosis : 22.3 and General inquiries : 22.6 percent of correlation with mental health's variable can be seen . R2's coefficient of determination indicates 1.8, 1.6, 3.7, 6.7, 5.1, 4.5, 4.4, 6.9, 5 and 5.1 percent of the dependent variable changes by the independent variable of children's quantity. Standardization coefficient shows, 1.4, 1.2, 3.2, 7.2, 4.7, 4, $3.9,6.5,4.5$ and 4.7 of the dependent variable of mental health by independent variable of children's number of respondents in statistical universe is explainable. Beta shows the relation between mental health and the number of children is reverse. This means how much number of respondent's children is more, mental health's disorders is less. In other words, how much the number of respondent's children is more, mental health is more. B indicates, for each unit increment in the independent variable how much dependent variable is increasing or decreasing. Therefore, according to $\mathrm{F}$ and $\mathrm{T}$ values and significance level the theory is accepted.

Table 8: study of the relationship between number of children and 10 dimension of women's mental health

\begin{tabular}{|l|c|c|c|c|c|c|c|c|c|}
\hline \multicolumn{1}{|c|}{ Mental health dimensions } & $\mathrm{R}$ & $\mathrm{R} 2$ & $\mathrm{R} 2 . \mathrm{Ad}$ & Standard error & $\mathrm{B}$ coefficient & Beta & Value of T & Value of $\mathrm{F}$ & Significance level \\
\hline hostility & 0.135 & 0.018 & 0.014 & 0.6858 & -0.071 & -0.135 & -2.022 & 4.088 & 0.044 \\
\hline somatization & 0.127 & 0.016 & 0.012 & 0.7094 & -0.069 & -0.127 & -1.891 & 3.574 & 0.06 \\
\hline mental and practical obsessive & 0.192 & 0.037 & 0.032 & 0.7039 & -0.104 & -0.192 & -2.89 & 8.351 & 0.004 \\
\hline interpersonal sensitivity & 0.276 & 0.076 & 0.072 & 0.6736 & -0.146 & -0.276 & -4.246 & 18.028 & 0.000 \\
\hline depression & 0.227 & 0.051 & 0.047 & 0.7188 & -0.127 & -0.227 & -3.447 & 11.879 & 0.001 \\
\hline anxiety & 0.211 & 0.045 & 0.04 & 0.775 & -0.127 & -0.211 & -3.199 & 10.235 & 0.002 \\
\hline anxiety in fear mood & 0.209 & 0.044 & 0.039 & 0.6736 & -0.109 & -0.209 & -3.17 & 10.046 & 0.002 \\
\hline paranoia & 0.263 & 0.069 & 0.065 & 0.7341 & -0.152 & -0.236 & -4.035 & 16.285 & 0.000 \\
\hline psychosis & 0.223 & 0.05 & 0.045 & 0.2612 & -0.107 & -0.223 & -3.38 & 11.424 & 0.001 \\
\hline General inquiries & 0.226 & 0.051 & 0.047 & 0.7633 & -0.134 & -0.226 & -3.427 & 11.747 & 0.001 \\
\hline
\end{tabular}

\section{Discussion and Conclusion}

Descriptive statistic's results shows that most of women of this study are 20-29 years old and its average is 28 years old. In terms of education, average education of women is 11 Class and their husband's average education is 10 . The average number of their children is 2.Based on statistical analysis, variables of work sharing, participate in decisions at home, families interfering in matrimony and number of children have a significant relationship with dimensions of mental health.

The first variable examined in this study related to the mental health is housework sharing at home that only in two parameters (mental and practical obsessive, depression) of the ten indicators of mental health is significant. This result is explained by theories of Erikson, Adler, Lewin and Rogers and is in same direction with findings of Soltanian and KHaghanian-Fard. By considering these statistics, it can be said that fatigue of working a lot and daily can cause depression and mental and practical obsessive of women. More than 90 percent of women living in the Gerash are housewives and this is firstly because most men do not want their wives to work at outside of the home, and secondly because women do not attempt for obtaining any job (because of lack of motivation and education). For this reason, most women spend their time by doing repetitive and boring works in their home. However, it is unclear whether or not anybody is grateful for their work at home. By doing these things does not remain any time for resting, thinking about themselves and improvement in life. So human by staying away from development and improvement gradually will encounter to extreme psychological fatigue or their mental health will compromised by spending remaining time with scattered works and without goal for long-term. So work sharing in the home will increase and strengthen their mental health. Because they have more time to address their progress and feel that others share her labor, and become familiar with difficulty of working at the home. From one side of view cooperation and collaboration in the works increase intimacy and interdependence among group members. Therefore, work sharing at home brings more peace and intimacy governs at environment of home and woman.

The second analyzed factor is women's involvement in decision-making at home and its relationship with women's 
mental health. The aim of this study of women's participation is the power that she thinks she has at home. In fact, that is in woman's mind, not identical. This variable is significantly related with all 10 indicators of mental health. According to statistics, how much she thinks she has more power and participation in decision-making and her views are considered, she tries more to act. Showing partial view or mooting it or in general thinking that she is important and useful causes their mental health influences also others that are influenced, somehow will influence with the idea of women. Greater participation in decision-making brings more mental health for women. How much her authority is more, her stress is less. This result is explained by theories of Erikson, Adler, Freud, and Rogers and is in same direction with findings of Soltanian and KHaghni-Fard.

The third variable is the relation of families interfering in personal and matrimony life with mental health of women. According to the obtained statistics, this variable has a significant relationship with the vast majority of indicators. It seems normal. How much rate of others' interfering in matrimony is high, that much tension will increase, When others involved in solving disputes of matrimony or are motivator of disputes, bringing back the situation to normal mood will be harder, because with a lot kindness are decreasing the need of man or woman to spouse's kindness and this causes they go far from each other day to day and from other side by wrong interposing they make the platform of tension and in fact instead of solving the problem and causing improvement in their relationship they make them ready to compromise with situation and accept the fact of their life and make them to accept that wife or husband is not a suitable person for them and they should compromise with them or make themselves ready for separation. These conditions will pose a risk for women's mental health and their mental health will be affected. It should be mentioned that in contrast of decreasing in the interfering of families in matrimony life in these days and changes in culture of Grash coeval with industrialization in all over of Iran but traditional culture of Grash let direct and indirect interfering of families in the matrimony life. This result is explained by theories of Adler, Lewin and Rogers and it is in same direction with findings of Soltanian and KHaghaniFard.

The fourth variable investigated in this study, is the number of respondent's children. According to the results of the study, the vast majority of indicators have a significant relation with this variable. How much the number of children is greater, women have a better mental health. This result has multi reasons. Some of the reasons are employment of women with children, children's help in different housework, being children at home as warmth of the family, satisfying mother's natural needs, being children as peace reason for mother at home, regardless of the concerns of not having children, or type of labor or growing up them, or treating with them as a wealth or investment for future and blessing of giving children to us as a deposit of God and this thinking that being worthy beside God for having and growing up one of his creatures and lots of other reasons that mothers have more children have a better mental health in comparing with other women. This result is explained by theories of Adler and Freud and it is in same direction with findings of SepehrManesh and Mosalla-Nejad and et al.

Generally achieving to mental health is not accidently but also achieving this goal needs time and effort. According to results obtained above, we can say in order, increase in women involvement in critical decision makings at home, nonexistence of others and families interfering in matrimony life, having children and housework sharing are strengthening the mental health of women and help them to manage a dynamic and healthy family. Subject which all the society will take advantage of it at last.

Besides, we should not forget that self-confidence is the key of mental health. In addition to increase of selfconfidence, decreasing anxiety, regular exercising, enough resting, using suitable foods, weight controlling and association with people that have positive energy and happy mentality, are increasing and strengthening mental health of people.

\section{Resources}

Adlyn et al (1999). Effect of methods of communication conflict resolution and problem solving strategies on mental health of students. The third seminar on mental health of students. Tehran.

Akuchekian, Shahla (1997). "Women mental health and women role model in Islamic attitudes." Tehran conference on religion effect on mental health. Navid Islam Publishing Office. Qom.

Asgharipoor, Hamid and Negar Asgharipoor and Manoochehr Fazlikhany (2004) Consultation with students in schools: skills and applications for teachers in Mashhad. Tehran, Zarih Aftab publications.

Babapoor, Khairuddin, Jalil, (2003). Effect of methods of communication conflict resolution and problem solving strategies on mental health of students, Iran.

Bahrainian S A, Nour Ali A. (2004) Interns' Health Assessment at Shahid Beheshti University of Medical Sciences. Journal of Research in Medical Sciences (Shahid Beheshti Medical School). 2004, Volume 28 (1): 65-70. 
Black,C,V,R,\&Clar,A.W.(1987)."Depressive disorder in primary care .British" Journal of Psychiatry, 150(18) 737- 51.

Herman, Hezler (1999). Effect of methods of communication conflict resolution and problem solving strategies on mental health of students. The third seminar on mental health of students.

Hosseini S H, Mousavi M H. (2007) "Comparison of medical and paramedical mental health of students." Journal of Gorgan's University of Medical Sciences.2007 Year 6 (13): 102-105.

Janani, Katayun. (2001). Survey the relationship between family interaction and mental health grade students in the city Borojerd year 78- 79. MA thesis. Tarbiat Modares University.

Khaghanifard, Mitra (2011). "The role of violence against women, gender socialization and social capital in predicting mental health of women in Tehran." Social Studies and Psychology of Women, 2011, Year 9, No. 2, fall, pp. 80-55.

Khodarahimi, S. (1994). Psychology of Aging, Astan Quds Razavi publications.

Khodarahimi, S. (1995). The concept of mental health, Javdan publications.

Lily Mossalanejad , Amir Kheshti, Ehsan Gholami (2007) " Survey of mental health of women during pregnancy and psychological related factors in Jahrom". Jahrom Journal of Medical Sciences, 2007, Volume 5, Fall \& Winter, No. 5: pp. 22-29.

Milanifar, Behrouz. (1991) Mental Health; Ghomes Publications; Tehran - p 267.

Najarian, Bahman and Davoodi, Iran (2001) SCL-25 construction and Validation (short form of the SCL -90). Journal of Psychology association. No. 18.

Noorbala A A. Kazem, M. (1999). National Survey of Health and Disease in Iran. National Research Center of Medical Sciences. Ministry of Health. Medical Education. Tehran. 1999. Pages 7 to 10.

Robinson KL, McBeth J, Macfarlane GJ. (2004) "Psychological distress and premature mortality in the general population: a prospective study". Ann Epidemiol. 2004; 14 (7): 467-72.

Sepehrmanesh, Zahra. (2009) mental health and its related factors in young women in Kashan city. Journal of Obstetrics, Gynecology and Infertility, Iran, 2009, Volume 12, spring, No. 1, pp. 31-41.

Soltanian, Alireza. Fatima Bahraini, Soudabeh Namazi, Mohammad Amiri, Hossein Ghaedi, Gholamreza Kohan (2004), " The mental health status of high school students in Bushehr province and its influencing factors in the 1382-1383 school year," Journal of South Medical. Bushehr University of Medical Sciences. 2004, Year 7 (2): 173-182.

Zarei, Eqbal (1994) comparison of the mental health of women in monogamous families with Polygamous families in Ahvaz. 